\title{
Patients Perception and Experience Undergoing Third Molar Removal - A Questionnaire Survey
}

\author{
M.Ovia ${ }^{1}$ and Madhulaxmi $\mathrm{M}^{2}$ \\ ${ }^{1}$ Saveetha Dental College, Saveetha Institute of Medical and Technical \\ Sciences, Saveetha University, Chennai 600077, India. \\ ${ }^{2}$ Department of Oral \& Maxillofacial Surgery, Saveetha Dental College, \\ Saveetha Institute of Medical and Technical Sciences, Saveetha University, \\ Chennai 600077, India.
}

\section{ABSTRACT}

Surgical removal of impacted third molars is one of the most common procedures carried out in oral surgery. The aim of this study was to determine the patient's perception and experience of undergoing third molar removal; and if gender had any association with the responses surveyed . A questionnaire based survey was done among patients who visited our institution during December 2019 - January 2020. Participants had to respond to fifteen questions which were made available in typed hardcopy format. The questions were distributed to analyse the patients reasons for seeking removal of third molar, the intraoperative and postoperative experience with relation to the extraction procedure. The datas were collected and entered to an Excel sheet followed by statistical analysis done in SPSS by IBM. The statistical test used was the Chi-square test. More than $60 \%$ respondents had dental fear while waiting in the lobby and prior to extraction. However after commencement of procedure and administrating LA, more than $80 \%$ were comfortable through the procedure. But again, postoperative discomfort was felt by $80 \%$ patients and more than 50\% patients were of the opinion that overall experience of third molar removal has increased their fear and anxiety to dental treatments. Hence, it may be important to incorporate altered protocols and novel techniques for removal of third molars.

KEY WORDS: THIRD MOLAR, EXTRACTION, SURGICAL REMOVAL, QUALITY OF LIFE.

\section{INTRODUCTION}

Dental anxiety is a recognised problem for both patients and dental health providers. Most people require extraction of the third molar due to pain, tooth decay or periodontal disease. Hence, third molar extraction

\section{ARTICLE INFORMATION}

*Corresponding Author: madhulaxmi@saveetha.com Received 27th July 2020 Accepted after revision 20th Sep 2020 Print ISSN: 0974-6455 Online ISSN: 2321-4007 CODEN: BBRCBA

Thomson Reuters ISI Web of Science Clarivate Analytics USA and Crossref Indexed Journal

\section{Clarivate
Analytics}

NAAS Journal Score 2020 (4.31) SJIF: 2020 (7.728)

A Society of Science and Nature Publication,

Bhopal India 2020. All rights reserved.

Online Contents Available at: http//www.bbrc.in/

Doi: http://dx.doi.org/10.21786/bbrc/13.8/106 is still one of the most frequent interventions in oral surgery (Sancho-Puchades et al., 2012; Savin and Ogden, 1997; Shafer et al., 1999). The most frequent indication for the extraction of third molars is pericoronitis. Other indications are infection, restorative reasons or caries, prophylactic indication or prevention of crowding are more controversial. Although impacted third molars may remain symptom-free indefinitely, they may be responsible for significant pathology(Sancho-Puchades et al., 2012; Savin and Ogden, 1997).

Patients undergoing surgical extraction of third molars suffer alterations in their daily routine because of pain and swelling(Coulthard, 2003; Ogden et al., 1998; White

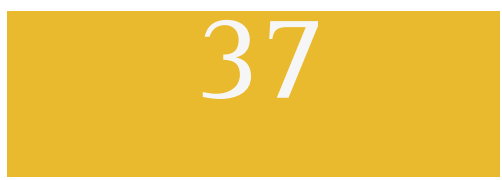


et al., 2003). Most third molar surgeries are performed without major complications. However, a major group of patients experience persistent pain and swelling with or without difficulty in mouth opening. Rarely but not uncommon, patients can also experience infection, dry socket, dentoalveolar fracture, paresthesia of the inferior alveolar nerve and of the lingual nerve, temporomandibular joint injury and even mandibular fracture. These complications can definitely affect the patients quality of life and further approach to future dental treatments. Quality of life is a difficult concept so that the result might have differences depending on individual perception (Colorado-Bonnin et al., 2006).

With a rich case bank established over 3 decades we have been able to publish extensively in our domain(Abdul Wahab et al., 2017; Abhinav et al., 2019; Eapen et al., 2017; J et al., 2018; Jain and Nazar, 2018; Marimuthu et al., 2018; Patil et al., 2017; Ramadorai et al., 2019; Senthil Kumar et al., 2019; Sweta et al., 2019; Wahab et al., 2018). Based on this inspiration we aimed to conduct a survey on patients perception and experience of undergoing third molar removal. However, the questionnaires to assess quality of life were designed to measure the quality, the effectiveness and the efficiency of the treatment methods as well as physical, psychological and social consequences for patients. The aim of this study was to determine the patient's perception and experience of undergoing third molar removal.

\section{MATERIAL AND METHODS}

This study was done as a questionnaire survey which was answered by the patients who visited our institution for suture removal post surgical removal of third molars. Fifteen questions were prepared which included two sets of questionnaires. Informed consent was taken from all participants who were willing to take the survey. Questionnaires were in English, and only those participants who could self read and answer were included in the study. Patients who did not know English, who had not had a surgical third molar removal and medically compromised patients were excluded from the study. Set 1questions included their personal details like age and gender. Set 2 included questions related to reason for extraction, how they felt before and during the extraction and while administering LA, their level of fear and its reason. Other questions like post extraction difficulty, level of anxiety and their attitude towards further dental treatments were also surveyed. 100 patients were included in the study. Datas were collected in a written format to avoid discussion and false results, thereby no bias was evidenced in the study. The datas were entered to an Excel sheet followed by statistical analysis done in SPSS by IBM. The statistical test used was the Chi-square test.

\section{RESULTS AND DISCUSSION}

Out of 100 patients who filled the survey $26 \%$ of them were females and remaining 74\% were males (Figure-1). $24 \%$ of participants were between 20-30years, 55\% of them were of 31-40 years and the remaining 21\% of them were between 41-50years of age (Figure-2). 55\% of the patients were between 31-40 years of age and 50\% of them were males which were observed higher which showed a statistically significant association of gender with age $(p=0.000)$ (Figure-3). 49\% have undergone extraction because of pain which was observed higher in males $(41 \%)$ which showed no significant association of gender with reason for extraction of wisdom tooth $(p=0.174)$ (Figure-4).

Figure 1: Shows the bar graph of the distribution of gender among the patients who filled the survey where $\mathrm{X}$-axis represents the Gender and $\mathrm{Y}$-axis represents the percentage of patients who filled the survey. $26 \%$ of them were females(red) and remaining 74\% were males(yellow).

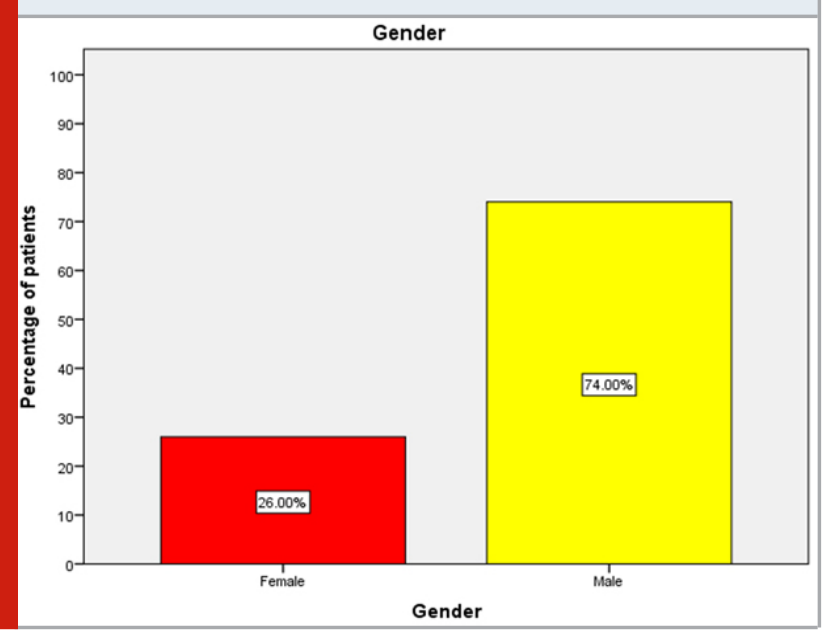

Figure 2: Shows the bar graph for distribution of age among the patients who filled the survey where $\mathrm{X}$-axis represents the age and Y-axis represents the percentage of patients who filled the survey. Of this $24 \%$ of them were of age group 20-30years (Brown), 55\% of them were of age group 31-40 years (Black) and remaining 21\% of them were between 41-50years (Golden yellow).

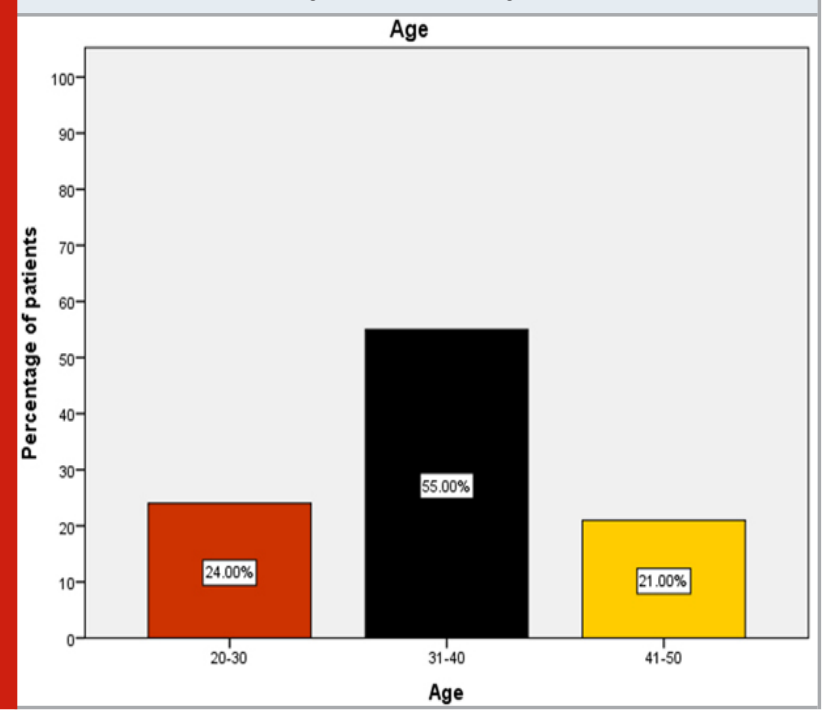


Figure 3: Shows the bar graph for association of gender with age,where $\mathrm{X}$-axis represents the gender and $\mathrm{Y}$-axis represents the no of patients who filled the survey. Of which 55\% of them were between 31-40 years(black) of age with 50\% males. Chi-square test was performed(Chisquare value - 76.375a , $\mathrm{p}=0.000$ ) which showed a significant association of gender with age $(\mathrm{p}<0.05)$.

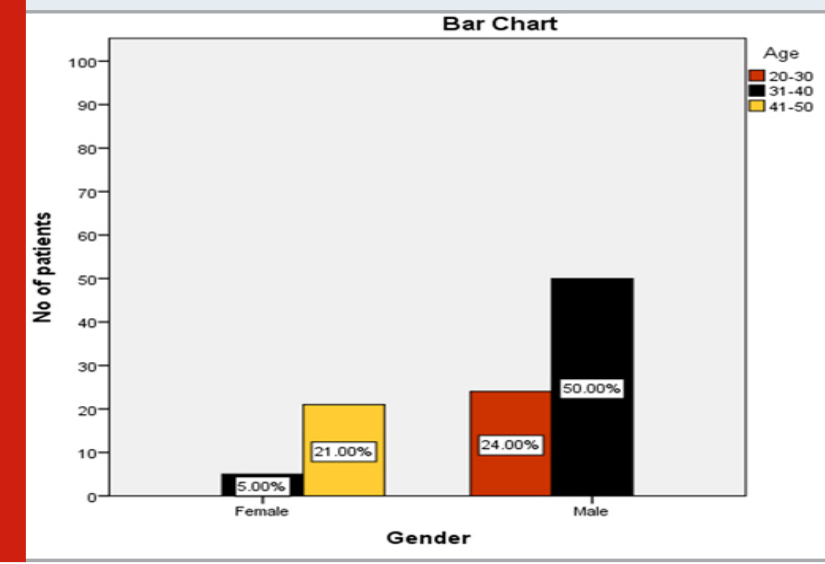

Figure 4: Shows the bar graph for association of gender with reason for extraction of wisdom tooth, where $\mathrm{X}$-axis represents the gender and $\mathrm{Y}$-axis represents the no of patients who filled the survey. $49 \%$ of them had undergone extraction because of pain(coral pink) with higher association of males(41\%). Chi-square test was performed(Chi-square value - 4.971a , p=0.174) which showed no significant association of gender with reason for extraction of wisdom tooth ( $p>0.05)$.

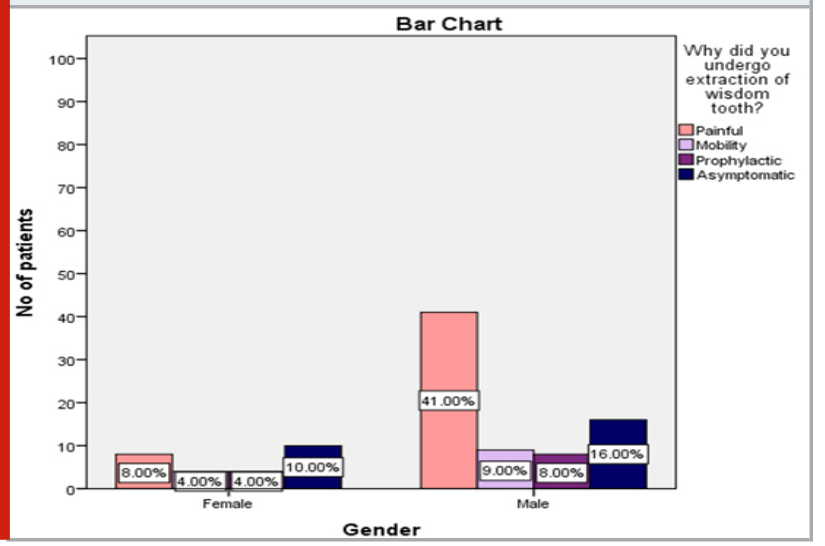

86\% did not experience pain after administering LA with higher male response(67\%) which showed a significant association of gender with experience of the pain after administration of LA $(p=0.027)$ (Figure-5). $42 \%$ of them experienced pain during extraction with a higher male response(34\%) but gender showed no significant association with extraction experience $(p=0.402)$ (Figure-6). 64\% of them experienced fear before extraction with higher male response (47\%) with no significant association of gender with fear before extraction ( $p=864$ ) (Figure-7). 41\% of them experienced fear for the treatment with higher male response(34\%) with no significant association of gender with reason of fear before extraction( $p=0.111$ ) (Figure-8).

Figure 5: Shows the bar graph for association of gender with experience of the pain after administration of LA, where $\mathrm{X}$-axis represents the gender and $\mathrm{Y}$-axis represents the number of patients who filled the survey. 86\% of them did not (No-Green) experience pain after administering LA with higher association of males(67\%). Chi-square test was performed(Chi-square value $-4.874 \mathrm{a}, \mathrm{p}=0.027$ ) which showed a significant association of gender with experience of the pain after administration of $\operatorname{LA}(\mathrm{p}<0.05)$.

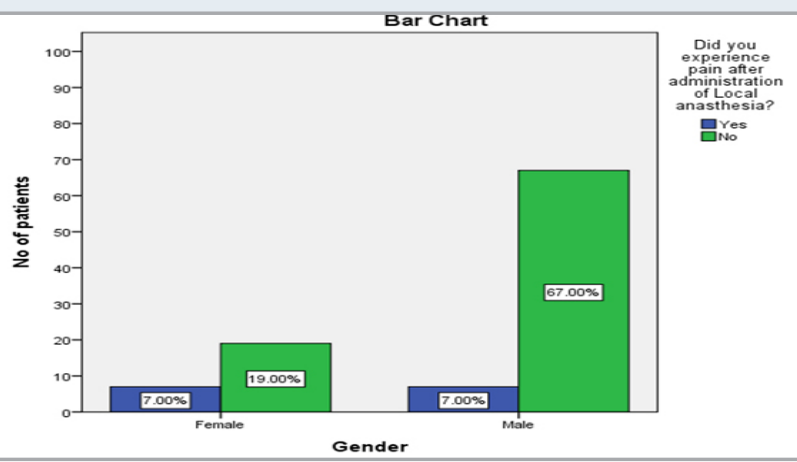

Figure 6: Shows the bar graph for association of gender with how the patients felt while undergoing extraction, where $\mathrm{X}$-axis represents the gender and $\mathrm{Y}$-axis represents the no of patients who filled the survey. $42 \%$ of them experienced pain(Maroon) during extraction with higher association of males(34\%). Chi-square test was performed(Chi-square value - $1.821 \mathrm{a}, \mathrm{p}=0.402$ ) which showed no significant association of gender with how they felt while undergoing extraction( $p>0.05)$.

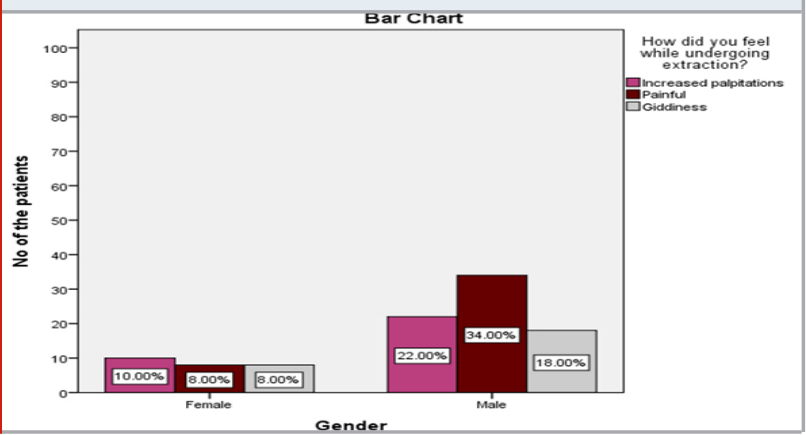

$70 \%$ of them felt uneasy in the waiting lobby before treatment with a higher male response(50\%) with no significant association of gender with how the patients felt in the waiting lobby( $\mathrm{p}=0.536)$ (Figure-9). $81 \%$ of them had discomfort post extraction with higher male response (62\%) with no significant association of gender with patients discomfort post extraction( $\mathrm{p}=0.231$ )(Figure10). $41 \%$ of the patients experienced swelling with higher male response(31\%) with no significant association of gender with the major difficulty patients experienced post extraction $(\mathrm{p}=0.825)$ (Figure-11). 
Figure 7: Shows the bar graph for association of gender with experience of the fear before extraction, where $\mathrm{X}$-axis represents the gender and $\mathrm{Y}$-axis represents the number of patients who filled the survey. $64 \%$ of them experienced fear(Yes-Blue) before extraction with higher association in male(47\%). Chi-square test was performed (Chi-square value $-0.029 \mathrm{a}, \mathrm{p}=0.864$ ) which showed no significant association of gender with previous experience of fear before extraction( $p>0.05)$.

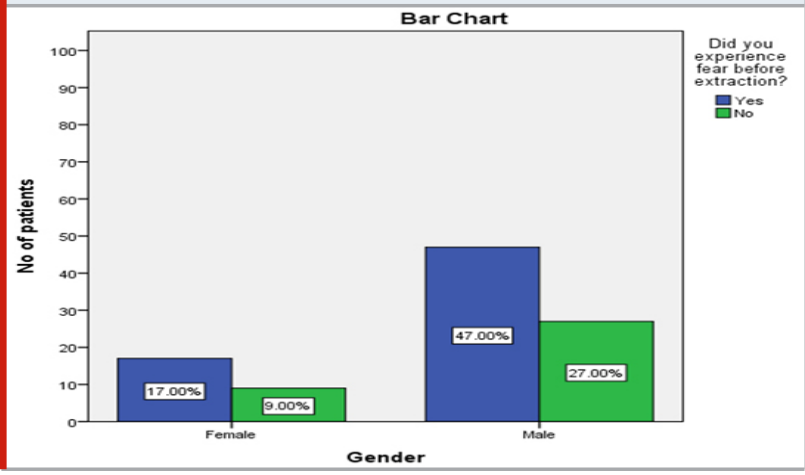

Figure 8: Shows the bar graph for association of gender with reason of fear before extraction, where $\mathrm{X}$-axis represents the gender and $\mathrm{Y}$-axis represents the number of patients who filled the survey. $41 \%$ of them experienced fear for the treatment(orange) with higher association in males(34\%). Chi-square test was performed(Chi-square value $-4.396 \mathrm{a}, \mathrm{p}=0.111$ ) which showed no significant association of gender with reason of fear before extraction( $p>0.05)$.

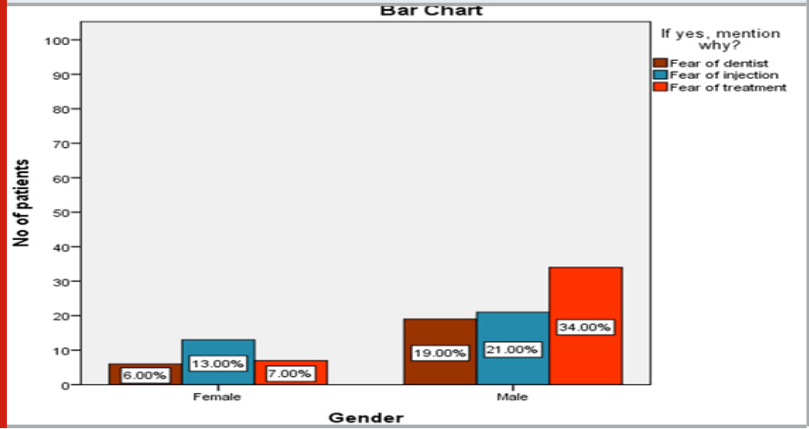

$46 \%$ of the patients were able to resume their normal activities within 5-10days with higher male response(37\%) with no significant association of gender with the major difficulty patients experienced post extraction $(p=0.158)$ (Figure-12). 80\% of the patients had no fear for future treatment with higher male response(62\%)with no significant association of gender with the fear of further dental treatments $(p=0.111)$ (Figure 13$) .77 \%$ of the patients felt that extraction had influenced the level of discomfort in their future dental treatments with higher male response(57\%)with no significant association of gender with the influence of extraction procedure in their future dental treatments( $\mathrm{p}=0.991)$ (Figure-14). 53\% of the patients had mentioned that their fear got increased with higher male response (47\%) with a higher significant association of gender with the level of fear and anxiety towards extraction( $p=0.000)$ (Figure-15).

Figure 9: Shows the bar graph for association of gender with how the patients felt in the waiting lobby, where $\mathrm{X}$-axis represents the gender and $\mathrm{Y}$-axis represents the number of patients who filled the survey. 70\% of them felt uneasy(gray) in the waiting lobby with higher association of males(50\%). Chi-square test was performed(Chi-square value $-1.247 \mathrm{a}, \mathrm{p}=0.536$ ) which showed no significant association of gender with how the patients felt in the waiting lobby $(\mathrm{p}>0.05)$.

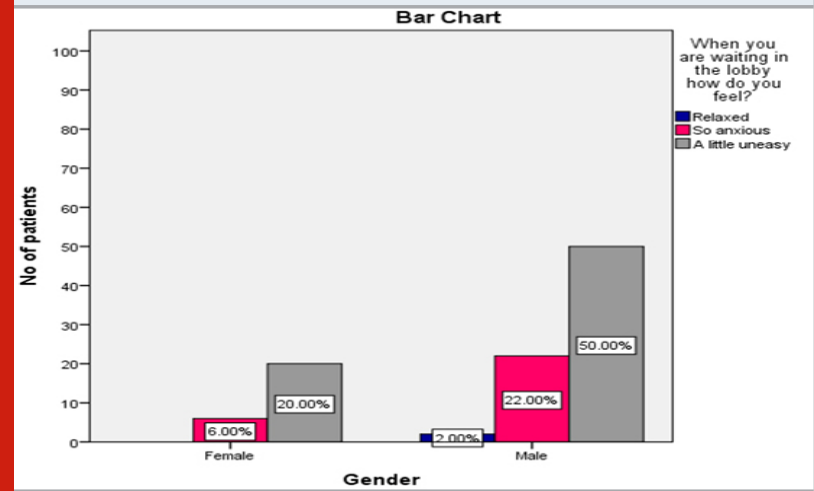

Figure 10: Shows the bar graph for association of gender with patients discomfort post extraction, where $\mathrm{X}$-axis represents the gender and $\mathrm{Y}$-axis represents the number of patients who filled the survey. $81 \%$ of them didn't have discomfort(No-Blue) post extraction in association with males(62\%). Chi-square test was performed(Chi-square value $-1.433 \mathrm{a}, \mathrm{p}=0.231$ ) which showed no significant association of gender with patients discomfort post extraction $(p>0.05)$.

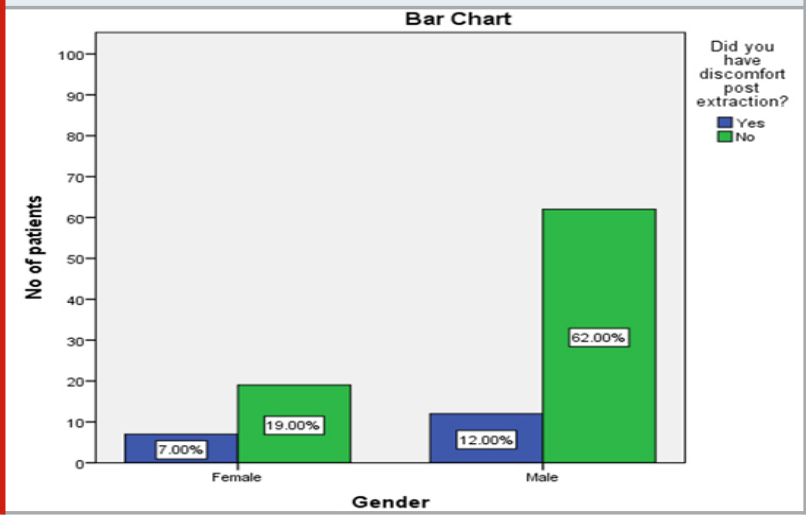

Out of 100 patients who filled the survey 74\% were males which was in consensus with studies showing that most of the patients who underwent extraction were males (Sancho-Puchades et al., 2012). Out of which 55\% were between 31-40 years, similar results were found that the mean age of patients who underwent extraction was found to be $39.8+/-13.6$ years(Chuang et al., 2007). More than 60\% respondents were uneasy and anxious while waiting in the lobby and prior to extraction which were 
similar to the results that increased anxiety prior to the actual experience wherein most of the patients feared before entering a dental clinic(Berggren, 1986; Stefano et al., 2020). However after commencement of procedure and administering LA, more than $80 \%$ were comfortable through the procedure and had no postoperative discomfort which was in consensus with studies that after administering LA patients felt comfortable for extraction with no postoperative discomfort(Kamatham et al., 2017) (Whitehead, 1996).

Figure 11: Shows the bar graph for association of gender with the major difficulty patients experienced post extraction, where $\mathrm{X}$-axis represents the gender and $\mathrm{Y}$-axis represents the number of patients who filled the survey. $41 \%$ of the patients experienced swelling(aqua blue) as their major difficulty post extraction with higher association of males(31\%). Chi-square test was performed(Chi-square value $-0.903 a, p=0.825$ ) which showed no significant association of gender with the major difficulty patients experienced post extraction( $p>0.05)$.

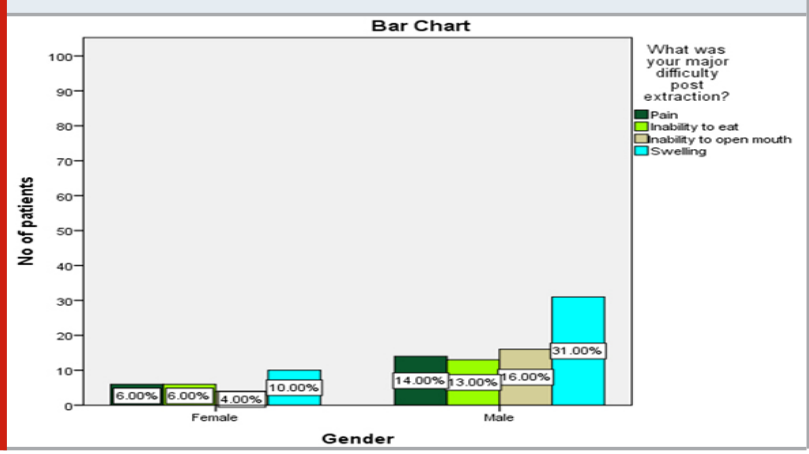

Figure 12: Shows the bar graph for association of gender with the time taken for resuming patients normal activity, where $\mathrm{X}$-axis represents the gender and $\mathrm{Y}$-axis represents the number of patients who filled the survey. $46 \%$ of the patients were able to resume their normal activities within 5-10days(dark pink) with higher association of males(37\%). Chi-square test was performed(Chi-square value $-5.202 \mathrm{a}, \mathrm{p}=0.158$ ) which showed no significant association of gender with the major difficulty patients experienced post extraction( $p>0.05)$.

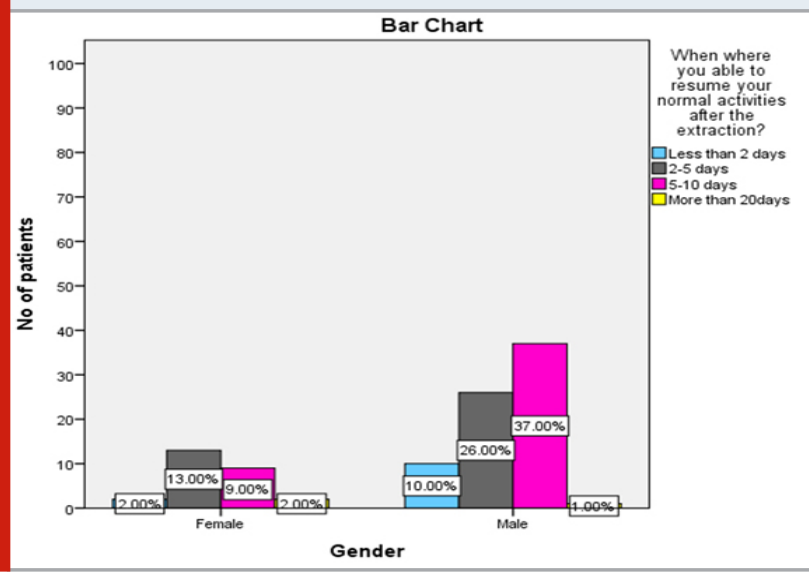

Figure 13: Shows the bar graph for association of gender with the fear of further dental treatments, where $\mathrm{X}$-axis represents the gender and Y-axis represents the number of patients who filled the survey. $80 \%$ of the patients had no(Green) fear for future treatment with higher association of male(62\%). Chi-square test was performed(Chi-square value $-2.547 \mathrm{a}, \mathrm{p}=0.111$ ) which showed no significant association of gender with the fear of further dental treatments( $p>0.05)$.

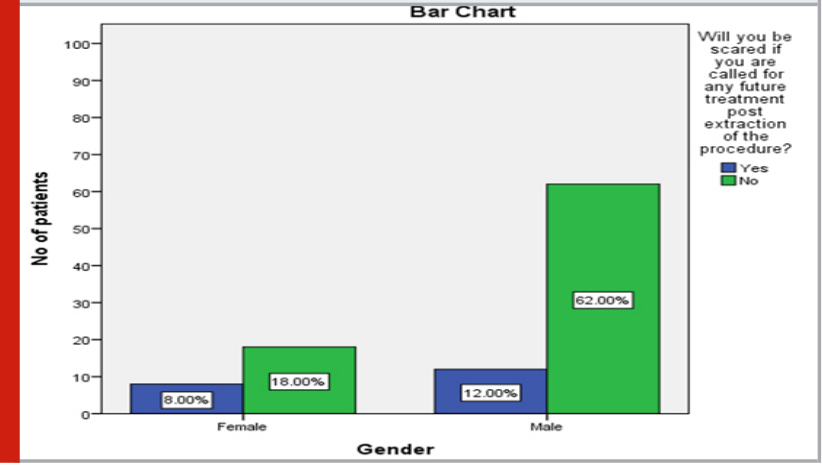

Figure 14: Shows the bar graph for association of gender with the influence of extraction procedure in their future dental treatments, where $\mathrm{X}$-axis represents the gender and Y-axis represents the number of patients who filled the survey. $77 \%$ of the patients felt that extraction had influenced the level of discomfort in future dental treatments (yes-Blue) with higher male response(57\%). Chi-square test was performed(Chi-square value - 0.000a , $\mathrm{p}=0.991$ ) which showed no significant association of gender with the influence of extraction procedure in their future dental treatments( $p>0.05)$.

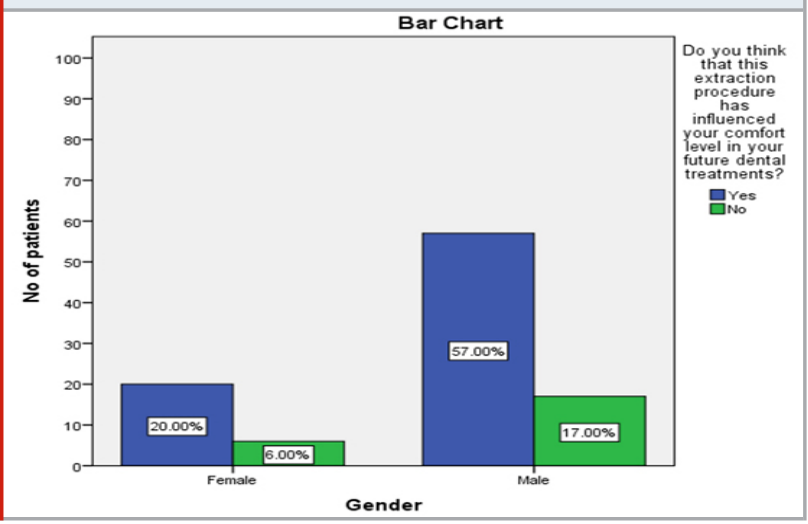

Among the post operative discomfort most patients complained swelling as a major difficulty which was in consensus with the other studies stating swelling as the major complication post extraction(Harbaugh et al., 2018; Roszkowski et al., 1997; Singh et al., 2014; Whitehead, 1996). However, 50\% of patients resumed normal activity in less than 5 days. Fear of future dental treatments were alleviated in $80 \%$ patients though level of anxiety has increased in more than 50\% patients after third molar removal which was in consensus with the studies that the level of fear and anxiety among the patients increased post extraction(Assad, 2020). 
Figure 15: Shows the bar graph for association of gender with the level of fear and anxiety towards extraction, where $\mathrm{X}$-axis represents the gender and $\mathrm{Y}$-axis represents the number of patients who filled the survey. 53\% of the patients had mentioned that their level of fear and anxiety increased(light orange) with higher association of males(47\%). Chi-square test was performed(Chi-square value - 23.531a , $\mathrm{p}=0.000$ ) which showed a significant association of gender with the level of fear and anxiety towards extraction $(\mathrm{p}<0.05)$.

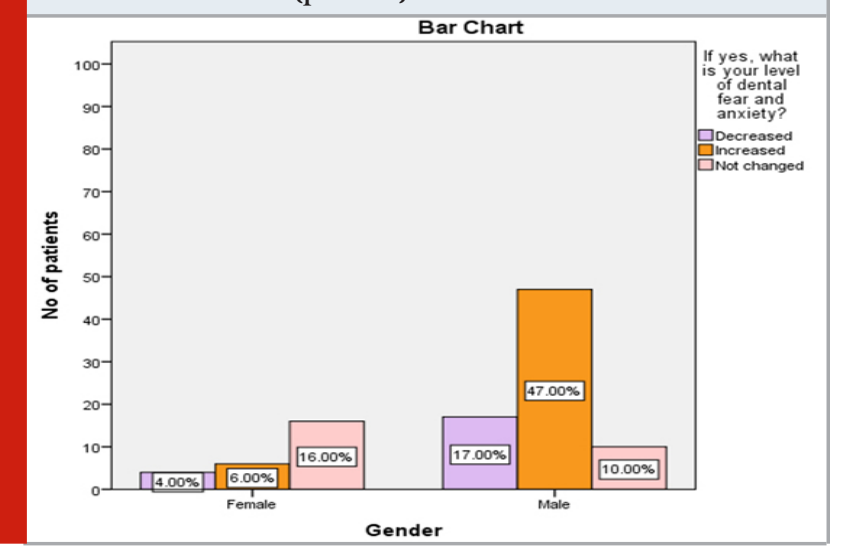

CONCLUSION

Based on the results of this survey study, it can be concluded that dental extraction still remains as one of the most feared and anxious procedure and there was no significant differences in the perception of pain, discomfort or anxiousness between both genders. Though patients move to a comfort level after local anesthesia and through the procedure, the post operative normalcy to routine activities is as late as ten days for many patients. Also, the experience of third molar removal actually increased their anxiousness when they had to seek further dental treatments. These findings infer the need to incorporate altered protocols and novel techniques for enabling a less stressful surgical procedure while removing third molars.

\section{ACKNOWLEDGEMENTS}

The authors thank all the participants who were part of the study for giving their responses willingly and enabling in undertaking this survey.

\section{Conflicts of Interest: Nil}

\section{REFERENCES}

Abdul Wahab PU, Senthil Nathan P, Madhulaxmi M, et al. (2017) Risk Factors for Post-operative Infection Following Single Piece Osteotomy. Journal of maxillofacial and oral surgery 16(3): 328-332.

Abhinav RP, Selvarasu K, Maheswari GU, et al. (2019) The Patterns and Etiology of Maxillofacial Trauma in South India. Annals of maxillofacial surgery 9(1): 114-117.

Assad T (2020) Oral Health Status and Attitude of
Patients towards Dental Extraction in Karachi. Pakistan Journal of Medicine and Dentistry. DOI: 10.36283/ pjmd9-3/011.

Berggren U (1986) Long-term Effects of Two Different Treatments forDental Fear and Avoidance. Journal ofDental Research. DOI: 10.1177/00220345860650060101.

Chuang S-K, Perrott DH, Susarla SM, et al. (2007) Age as a risk factor for third molar surgery complications. Journal of oral and maxillofacial surgery: official journal of the American Association of Oral and Maxillofacial Surgeons 65(9): 1685-1692.

Colorado-Bonnin M, Valmaseda-Castellón E, BeriniAytés L, et al. (2006) Quality of life following lower third molar removal. International Journal of Oral and Maxillofacial Surgery. DOI: 10.1016/j. ijom.2005.08.008.

Coulthard P (2003) Master Dentistry: Oral and Maxillofacial Surgery, Radiology, Pathology, and Oral Medicine.

Eapen BV, Baig MF and Avinash S (2017) An Assessment of the Incidence of Prolonged Postoperative Bleeding After Dental Extraction Among Patients on Uninterrupted Low Dose Aspirin Therapy and to Evaluate the Need to Stop Such Medication Prior to Dental Extractions. Journal of maxillofacial and oral surgery 16(1): 48-52.

Harbaugh CM, Nalliah RP, Hu HM, et al. (2018) Persistent Opioid Use After Wisdom Tooth Extraction. JAMA. DOI: 10.1001/jama.2018.9023.

Jain M and Nazar N (2018) Comparative Evaluation of the Efficacy of Intraligamentary and Supraperiosteal Injections in the Extraction of Maxillary Teeth: A Randomized Controlled Clinical Trial. The journal of contemporary dental practice 19(9): 1117-1121.

J PC, Marimuthu T, C K, et al. (2018) Prevalence and measurement of anterior loop of the mandibular canal using CBCT: A cross sectional study. Clinical implant dentistry and related research 20(4): 531-534.

Kamatham R, Deepak V, Challa R, et al. (2017) Comparison of a new auto-controlled injection system with traditional syringe for mandibular infiltrations in children: A randomized clinical trial. Anesthesia: Essays and Researches. DOI: 10.4103/0259-1162.194535.

Marimuthu M, Andiappan M, Wahab A, et al. (2018) Canonical Wnt pathway gene expression and their clinical correlation in oral squamous cell carcinoma. Indian journal of dental research: official publication of Indian Society for Dental Research 29(3): 291-297. Ogden GR, Bissias E, Ruta DA, et al. (1998) Quality of life following third molar removal: a patient versus professional perspective. British Dental Journal. DOI: 10.1038/sj.bdj.4809827.

Patil SB, Durairaj D, Suresh Kumar G, et al. (2017) Comparison of Extended Nasolabial Flap Versus Buccal Fat Pad Graft in the Surgical Management of Oral Submucous Fibrosis: A Prospective Pilot Study. Journal of maxillofacial and oral surgery 16(3): 312-321. 
Ramadorai A, Ravi P and Narayanan V (2019) Rhinocerebral Mucormycosis: A Prospective Analysis of an Effective Treatment Protocol. Annals of maxillofacial surgery 9(1): 192-196.

Roszkowski MT, Swift JQ and Hargreaves KM (1997) Effect of NSAID administration on tissue levels of immunoreactive prostaglandin E2, leukotriene B4, and (S)-flurbiprofen following extraction of impacted third molars. Pain 73(3): 339-345.

Sancho-Puchades M, Valmaseda-Castellón E, BeriniAytés L, et al. (2012) Quality of life following third molar removal under conscious sedation. Medicina oral, patologia oral y cirugia bucal 17(6): e994-9.

Savin J and Ogden GR (1997) Third molar surgery-a preliminary report on aspects affecting quality of life in the early postoperative period. British Journal of Oral and Maxillofacial Surgery. DOI: 10.1016/s02664356(97)90042-5.

Senthil Kumar MS, Ramani P, Rajendran V, et al. (2019) Inflammatory pseudotumour of the maxillary sinus: clinicopathological report. Oral Surgery 12(3): 255-259.

Shafer DM, Frank ME, Gent JF, et al. (1999) Gustatory function after third molar extraction. Oral Surgery, Oral Medicine, Oral Pathology, Oral Radiology, and Endodontology. DOI: 10.1016/s1079-2104(99)70240-4.
Singh N, Agrawal A, Yadav A, et al. (2014) Wisdom Tooth-Complications in Extraction. The Journal of Contemporary Dental Practice. DOI: 10.5005/jpjournals-10024-1484.

Stefano RD, De Stefano R, Bruno A, et al. (2020) Fear and anxiety managing methods during dental treatments: a systematic review of recent data. Minerva Stomatologica. DOI: 10.23736/s0026-4970.19.04288-2.

Sweta VR, Abhinav RP and Ramesh A (2019) Role of Virtual Reality in Pain Perception of Patients Following the Administration of Local Anesthesia. Annals of maxillofacial surgery 9(1): 110-113.

Wahab PUA, Madhulaxmi M, Senthilnathan P, et al. (2018) Scalpel Versus Diathermy in Wound Healing After Mucosal Incisions: A Split-Mouth Study. Journal of oral and maxillofacial surgery: official journal of the American Association of Oral and Maxillofacial Surgeons 76(6): 1160-1164.

Whitehead PN (1996) Local anaesthesia for pain relief following wisdom teeth extraction under general anaesthesia. Anaesthesia. DOI: 10.1111/j.13652044.1996.tb07719.x.

White RP, Shugars DA, Shafer DM, et al. (2003) Recovery after third molar surgery: Clinical and healthrelated quality of life outcomes. Journal of Oral and Maxillofacial Surgery. DOI: 10.1053/joms.2003.50106. 